\title{
Intake of Potentially Anticarcinogenic Flavonoids and Their Determinants in Adults in The Netherlands
}

\author{
Michaël G. L. Hertog, Peter C. H. Hollman, Martijn B. Katan, and Daan \\ Kromhout
}

\begin{abstract}
Flavonoids are strong antioxidants that occur naturally in foods and can inhibit carcinogenesis in rodents. Accurate data on population-wide intakes of flavonoids are not available. Here, using data of the Dutch National Food Consumption Survey 1987-1988, we report the intake of the potentially anticarcinogenic flavonoids quercetin, kaempferol, myricetin, apigenin, and luteolin among 4,112 adults. The flavonoid content of vegetables, fruits, and beverages was determined by high-performance liquid chromatography. In all subjects, average intake of all flavonoids combined was $23 \mathrm{mg} / \mathrm{day}$. The most important flavonoid was the flavonol quercetin (mean intake $16 \mathrm{mg} /$ day). The most important sources of flavonoids were tea (48\% of total intake), onions $(29 \%)$, and apples (7\%). Flavonoid intake did not vary between seasons; it was not correlated with total energy intake $(r=0.001)$, and it was only weakly correlated with the intake of vitamin $A$ (retinol equivalents, $r=0.14)$, dietary fiber $(r=0.21)$, and vitamin $C(r=0.26)$. Our use of new analytic technology suggests that in the past flavonoid intake has been overestimated fivefold. However, on a milligram-per-day basis, the intake of the antioxidant flavonoids still exceeded that of the antioxidants $\beta$-carotene and vitamin $E$. Thus flavonoids represent an important source of antioxidants in the human diet.
\end{abstract}

(Nutr Cancer 20, 21-29, 1993)

\section{Introduction}

Flavonoids are diphenylpropanoids (Figure 1) that occur ubiquitously in plant foods and are important constituents of the human diet. Although flavonoids are generally considered to be nonnutritive agents, interest in flavonoids has arisen because of their potential role in the preyention of human cancer. Flavonoids are strong antioxidants $(1,2)$ and scavengers of free radicals $(3,4)$, which are possibly involved in cell damage and tumor promotion $(5,6)$. Quercetin and other related flavonoids inhibited carcinogen-induced tumors in rats and mice $(7-10)$. Quercetin also inhibited proliferation of human colon cancer cells $(11,12)$. Some

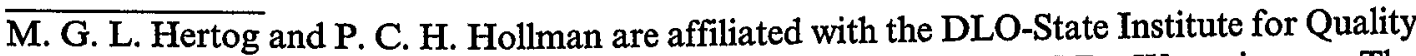
Control of Agricultural Products (RIKILT-DLO), NL-6708 PD Wageningen, The Netherlands. M. B. Katan (and also M. G. L. Hertog) is affiliated with the Department of Human Nutrition, Wageningen Agricultural University, NL-6703 HD Wageningen, The Netherlands. D. Kromhout (and also M. G. L. Hertog) is affiliated with the Division of Public Health Research, National Institute of Public Health and Environmental Protection, 3720 BA Bilthoven, The Netherlands.

Copyright $(\mathcal{C}$ 1993, Lawrence Erlbaum Associates, Inc. 


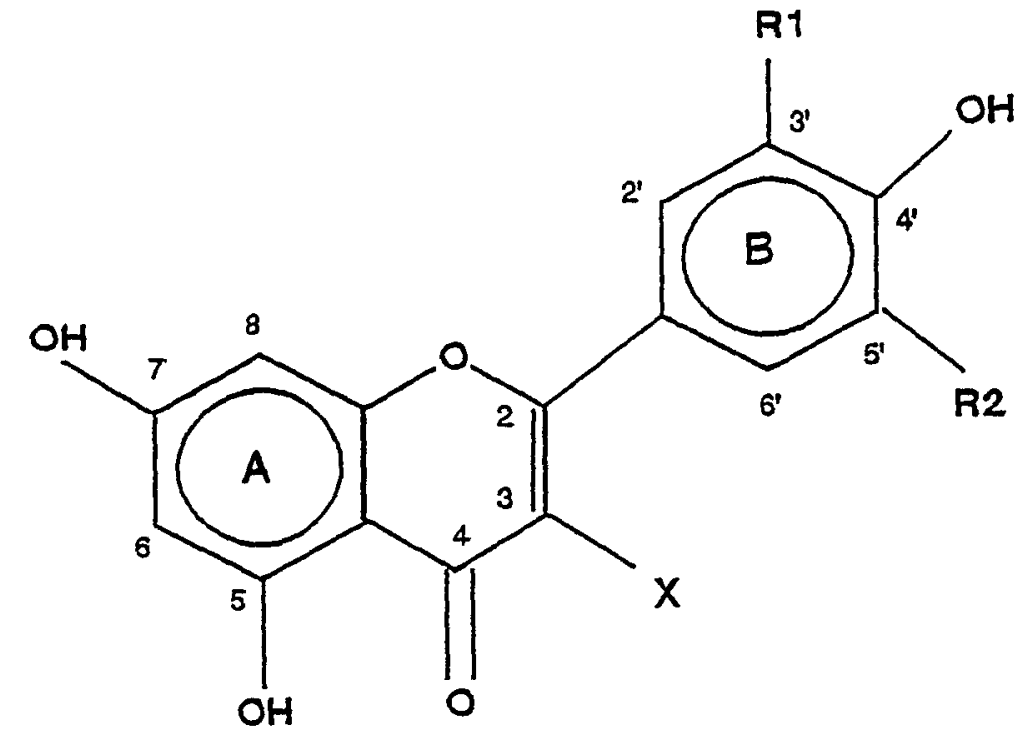

Figure 1. Structure of flavonoids. Flavonols: $X=O H$; quercetin: $R 1=O H, R 2=H$; kaempferol: $R 1=H, R 2=H$; myricetin: $\mathrm{R} 1=\mathrm{OH}, \mathrm{R} 2=\mathrm{OH}$. Flavones: $\mathrm{X}=\mathrm{H}$; apigenin: $\mathrm{R} 1=\mathrm{H}, \mathrm{R} 2=\mathrm{H}$, luteolin: $\mathrm{R} 1=\mathrm{OH}, \mathrm{R} 2=\mathrm{H}$.

flavonoids (e.g., quercetin) were also mutagenic in bacterial test systems $(13,14)$, but quercetin was not mutagenic in vivo (15). Quercetin at a level of $2 \%$ in the diet was found to induce bladder tumors in rats (16); however, these results could not be confirmed in other studies using quercetin levels up to $10 \%$ of the diet (17-19).

In a large number of epidemiological studies investigating relationships between diet and cancer, a protective effect of the consumption of vegetables and fruits on various types of cancer has been found (20). This protective effect has been generally attributed to the antioxidative capacities of vitamin $\mathrm{C}$ and $\beta$-carotene present in these foods (21). However, the significance of other potentially protective compounds, such as flavonoids present in vegetables and fruits, has become an important issue (22). Until now, epidemiological studies on the effects of flavonoids on human health have not been carried out because of a lack of accurate data on flavonoid content of common foods and intake in humans. Kühnau (23) estimated that the combined intake of flavonoids is approximately $1 \mathrm{~g} /$ day. However, this estimation was based mainly on food analyses using techniques of doubtful accuracy. Furthermore, no information is available on the intake of individual flavonoids such as quercetin.

Flavonoids consist mainly of anthocyanidins, flavonols, flavones, catechins, and flavanones $(24,25)$. We selected three major flavonols, quercetin, kaempferol, and myricetin, and two major flavones, luteolin and apigenin, because these flavonoids were most widely investigated in studies on anticarcinogenesis in experimental animals. We developed and validated a quantitative method for the determination of these flavonoids in foods (26), and we determined the flavonoid content of foods commonly consumed in The Netherlands $(27,28)$. We now report the intake of these flavonoids and their determinants in a large representative population sample in The Netherlands.

\section{Materials and Methods}

\section{Food Consumption Survey}

The Dutch National Food Consumption Survey was carried out among a representative sample of 5,898 individuals, aged 1-74 years, between April 1987 and March 1988. In the present study, we only used data of adults $>19$ years of age $(n=4,112)$. Institutionalized 


\begin{tabular}{|lcr|}
\hline \multicolumn{2}{|l|}{ Table 1. Daily Intake of Selected Nutrients and Consumption of Selected Food } \\
\multicolumn{2}{|l|}{ Groups (Dutch Food Consumption Survey, 1987-1988) } \\
\hline Nutrients and Food Groups & Men $(n=1,896)$ & Women $(n=2,216)$ \\
\hline Total energy & & \\
MJ/day & $11.5 \pm 2.9$ & $8.5 \pm 2.4$ \\
kcal/day & $2,745 \pm 692$ & $2,047 \pm 570$ \\
Fat, \% of energy & $40.5 \pm 6.8$ & $41.1 \pm 7.4$ \\
Protein, \% of energy & $13.1 \pm 2.8$ & $14.3 \pm 3.6$ \\
Carbohydrate, \% of energy & $41.2 \pm 7.1$ & $41.8 \pm 7.6$ \\
Alcohol, \% of energy & $5.2 \pm 5.9$ & $2.8 \pm 4.7$ \\
Dietary fiber, g/day & $27.0 \pm 9.7$ & $21.7 \pm 7.2$ \\
Vitamin C, mg/day & $76.4 \pm 56.6$ & $76.8 \pm 52.3$ \\
Retinol equivalents, mg/day & $1.1 \pm 0.8$ & $0.9 \pm 0.7$ \\
Vegetables, g/day & $163 \pm 105$ & $154 \pm 102$ \\
Fruits, g/day & $152 \pm 155$ & $186 \pm 161$ \\
Legumes, g/day & $8 \pm 33$ & $7 \pm 28$ \\
Nonalcoholic beverages, g/day & $1,115 \pm 429$ & $1,109 \pm 447$ \\
Alcoholic beverages, g/day & $383 \pm 520$ & $94 \pm 193$ \\
\hline a: Values are means \pm SD of 4,112 adults. & & \\
\hline
\end{tabular}

subjects and subjects who could not speak Dutch were not eligible. Design and methods of this survey are described in detail elsewhere (29). Information on food intake was collected by specially trained dietitians using a two-day record. Information on special dietary practices and smoking habits was also collected. Data collection was equally distributed over the seven days of the week and over the year (holidays excluded). Average nutrient intake per day was calculated using the 1986-1987 release of the Dutch Food Composition Data Bank. Table 1 reports intake of some nutrients and some selected food groups. These values are comparable to those obtained in other Western countries including the United States (30).

\section{Food Analysis}

Quercetin, kaempferol, myricetin, luteolin, and apigenin were determined by reverse-phase high-performance liquid chromatography (RP-HPLC) in 28 types of vegetables, 12 types of fruits, and 9 types of beverages (26-28). The sampling included foods that are often associated with low risk of cancer, such as green-yellow vegetables, cruciferous vegetables, and citrus fruits (31), and are commonly consumed in The Netherlands. Sampling of each of the vegetables and fruits was carried out in three seasons: spring, summer, and winter. Each food was purchased in a supermarket, in a grocery, and in an open-air street market, combined per food into a composite, and analyzed. Canned and other processed foods ( 3 brands of each food) were bought in a supermarket and combined into composites before analysis. Six different types of tea (prepared according to Dutch customs), five types of wine, and four types of fruit juice were analyzed. Coffee was analyzed additionally, but flavonoid levels in coffee were below the limit of detection $(<0.5 \mathrm{mg} / \mathrm{l})(28)$.

The method of analysis (26-28) consisted of extraction and acid hydrolysis of the flavonoid glycosides with $\mathrm{HCl}$ in $50 \%$ aqueous methanol followed by RP-HPLC and ultraviolet detection of the flavonoid aglycones. Identification and quantification of the flavonoids was performed by cochromatography with pure standards. In addition, identity and purity of the flavonoids were confirmed by diode-array detection on-line. Analytic quality control was performed by including control samples with a known amount of flavonoids in every series of analysis. Limit of detection for all flavonoids was approximately $1 \mathrm{mg} / \mathrm{kg}$ of fresh food. The mean flavonoid content, expressed as aglycons, of some selected foods is reported in Table 2. Additional data have been published elsewhere (26-28). 
Table 2. Flavonoid Content of Selected Fresh Vegetables, Fruits, and Beverages Commonly Consumed in the Netherlands ${ }^{a}$

\begin{tabular}{|c|c|c|c|c|c|}
\hline Food & Quercetin & Kaempferol & Myricetin & Apigenin & Luteolin \\
\hline Lettuce & $14 \pm 14$ & $<2$ & $<1$ & $<2$ & $<1$ \\
\hline Onion & $347 \pm 63$ & $<2$ & $<1$ & $<2$ & $<1$ \\
\hline Endive & $<1$ & $46 \pm 42$ & $<1$ & $<2$ & $<1$ \\
\hline Broad beans $^{b}$ & 20 & $<2$ & 25 & $<2$ & $<1$ \\
\hline Celery & $<1$ & $<2$ & $<1$ & 108 & 22 \\
\hline Apple ${ }^{c}$ & $36 \pm 19$ & $<2$ & $<1$ & $<2$ & $<1$ \\
\hline Wine (red) ${ }^{c, d}$ & $11 \pm 5$ & $<1$ & $9 \pm 3$ & $<1$ & $<0.5$ \\
\hline Tea (black) & $20 \pm 2$ & $14 \pm 3$ & $2.5 \pm 1.2$ & $<1$ & $<0.5$ \\
\hline Apple juice ${ }^{b-d}$ & 2.8 & $<1$ & $<0.5$ & $<1$ & $<0.5$ \\
\hline \multicolumn{6}{|c|}{$\begin{array}{l}\text { a: Values are means } \pm \mathrm{SD} \text { in } \mathrm{mg} / \mathrm{kg} ;<0.5,<1 \text {, and }<2 \text { are below limit of detection. } \\
b: \text { Sampled only once. } \\
c: \text { Means } \pm \mathrm{SD} \text { of } 5 \text { varieties. } \\
d \text { : Expressed in } \mathrm{mg} / \text {. }\end{array}$} \\
\hline
\end{tabular}

\section{Calculation of Flavonoid Intake}

Individual flavonoid intake was calculated by multiplying the consumption of each food by its flavonoid content. Flavonoid content was known for approximately $95 \%$ of all flavonoid-containing foods that are commonly consumed in The Netherlands. Individual intake of a particular fresh food was calculated by adding the amounts of raw and prepared food consumed, with weight losses due to preparation taken into account. We did not correct for loss of flavonoids due to preparation, because in a preliminary study flavonoids proved to be heat stable, with losses $<20 \%$ (unpublished observations). For most foods, the year mean value of the flavonoid content was used, because seasonal variability proved to be low. However, for fresh leafy vegetables such as lettuce, leek, and endive, season-specific values were used. Statistical analyses were carried out using the SAS statistical package (version 6) (32). Spearman's rank correlations between flavonoid intake and selected nutrients were computed.

\section{Results}

Average intake of flavonoids was $23 \mathrm{mg} /$ day (10th and 90th percentiles: 4 and $46 \mathrm{mg} /$ day). Seventy-six participants (2\%) had a flavonoid intake of $0 \mathrm{mg} /$ day on the two particular days on which they were surveyed. Quercetin contributed about $70 \%$ of flavonoid intake, kaempferol $17 \%$, myricetin $6 \%$, and luteolin and apigenin $4 \%$ and $3 \%$, respectively. Mean intake of quercetin was $16 \mathrm{mg} /$ day (10th and 90th percentiles: 3 and $34 \mathrm{mg} /$ day). Total flavonoid and quercetin intake varied only slightly by age and sex (Table 3). Intake was highest in the oldest age strata and tended to be higher in women than in men. The median and percentiles indicate that flavonoid intake is strongly skewed toward the higher values. This is also reflected in Figure 2, which shows the distribution of flavonoid intake of the total population.

Flavonoid intake was approximately $21 \%$ lower in heavy smokers than in nonsmokers or light smokers (Table 4). Male vegetarians had a $36 \%$ and female vegetarians a $43 \%$ higher intake of flavonoids than nonvegetarians. Mean flavonoid intake in summer and fall was 22 $\mathrm{mg} / \mathrm{day}$, and in winter and in spring it was $23 \mathrm{mg} /$ day.

Table 5 lists the top 10 foods contributing to total flavonoid intake. Tea was the major source of flavonoids at $48 \%$, followed by onions at $29 \%$ and apples at $7 \%$. We also investigated 


\begin{tabular}{|c|c|c|c|c|c|c|c|c|c|}
\hline & \multirow[b]{3}{*}{$\mathbf{n}$} & \multirow[b]{3}{*}{ Mean } & \multicolumn{3}{|c|}{ Flavonoids ${ }^{b}$} & \multicolumn{4}{|c|}{ Quercetin } \\
\hline & & & \multicolumn{3}{|c|}{ Percentile } & \multirow[b]{2}{*}{ Mean } & \multicolumn{3}{|c|}{ Percentile } \\
\hline & & & 10th & 50th & 90th & & 10th & 50th & 90th \\
\hline \multicolumn{10}{|c|}{ Men } \\
\hline All ages & 1,896 & 22 & 3 & 17 & 46 & 16 & 2 & 11 & 35 \\
\hline $20-39$ yrs & 901 & 21 & 3 & 15 & 47 & 16 & 1 & 10 & 36 \\
\hline $40-59$ yrs & 641 & 22 & 3 & 17 & 45 & 15 & 2 & 11 & 35 \\
\hline$\geq 60 \mathrm{yrs}$ & 354 & 24 & 6 & 21 & 46 & 16 & 4 & 13 & 33 \\
\hline All ages & \multicolumn{9}{|c|}{ Women } \\
\hline $20-39$ yrs & 1,083 & 23 & 5 & 20 & 45 & 16 & 3 & $\begin{array}{l}13 \\
12\end{array}$ & $\begin{array}{l}33 \\
34\end{array}$ \\
\hline $40-59$ yrs & 706 & 23 & 4 & 18 & 48 & 16 & 2 & $\begin{array}{l}12 \\
13\end{array}$ & $\begin{array}{l}34 \\
32\end{array}$ \\
\hline$\geq 60$ yrs & 427 & $\begin{array}{l}24 \\
25\end{array}$ & 5 & 20 & 45 & $\begin{array}{l}16 \\
16\end{array}$ & $\begin{array}{l}3 \\
5\end{array}$ & 14 & $\begin{array}{l}32 \\
31\end{array}$ \\
\hline & & 25 & 8 & 23 & 43 & 10 & & & 31 \\
\hline
\end{tabular}

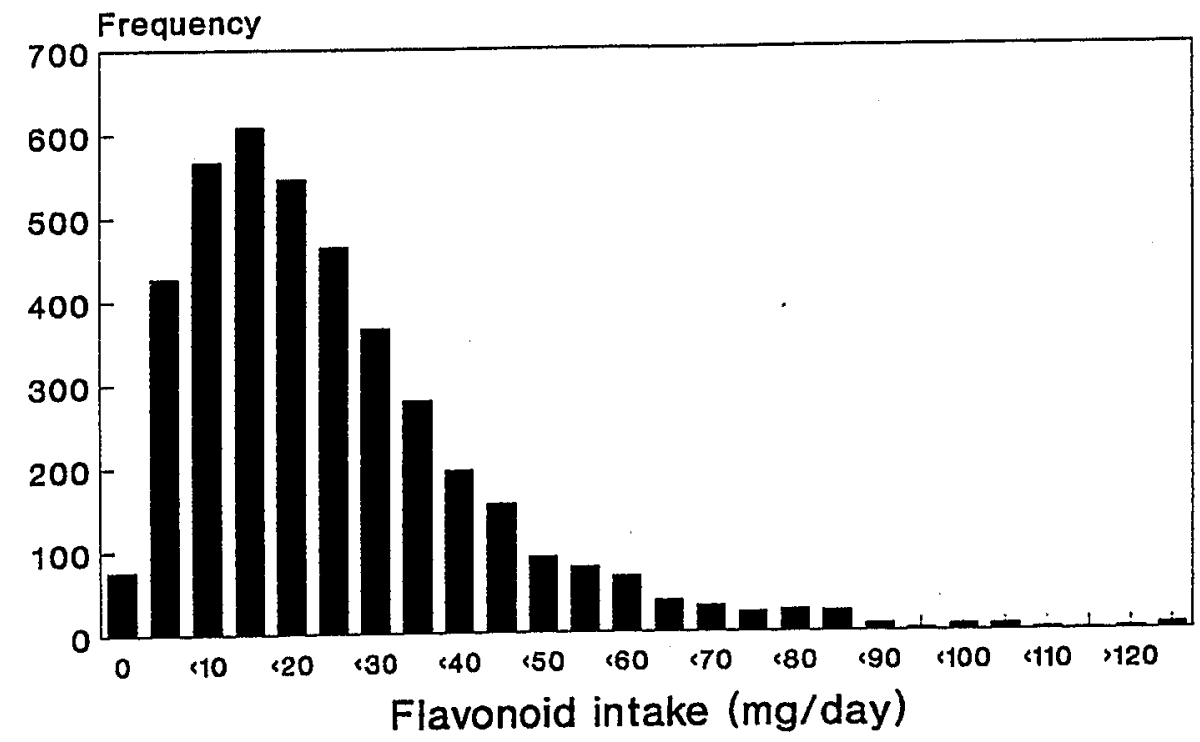

Figure 2. Histogram of flavonoid intake of 4,112 adults interviewed in Dutch National Food Consumption Survey, 1987-1988.

the contribution of different foods in a subgroup of subjects consuming $>50 \mathrm{mg}$ of flavonoids per day. Mean flavonoid intake in this subgroup was $68 \mathrm{mg} /$ day. Tea and onions remained the most important sources, followed by kale. All beverages combined accounted for about $50 \%$ of flavonoid intake, whereas vegetables accounted for $40 \%$ and fruits for $10 \%$. Flavonoid intake was not correlated with total energy intake $(r=0.001, p>0.05)$ and only weakly with intake of vitamin A (retinol equivalents; $r=0.14, p<0.01$ ), dietary fiber $(r=0.21, p<0.01$ ), and vitamin $\mathrm{C}(r=0.26, p<0.01)$. 


\begin{tabular}{|c|c|c|c|c|}
\hline & \multicolumn{2}{|c|}{ Men $(n=1,896)$} & \multicolumn{2}{|c|}{ Women $(n=2,216)$} \\
\hline & $n$ & $\begin{array}{l}\text { Flavonoid Intake, } \\
\text { mg/day }\end{array}$ & $n$ & $\begin{array}{c}\text { Flavonoid Intake, } \\
\text { mg/day }\end{array}$ \\
\hline \multicolumn{5}{|c|}{ Smokers } \\
\hline \multicolumn{5}{|c|}{ Cigarettes/day } \\
\hline 0 & 1,000 & 23 & 1,413 & 25 \\
\hline $1-9$ & 318 & 23 & 242 & 22 \\
\hline$>10$ & 578 & 18 & 561 & 20 \\
\hline \multicolumn{5}{|c|}{ Vegetarians } \\
\hline Yes & 32 & 30 & 63 & 33 \\
\hline No & 1,864 & 22 & 2,153 & 23 \\
\hline
\end{tabular}

Table 5. Contribution of Various Foods to Flavonoid Intake in Adults and in a Subgroup Consuming $>50 \mathrm{mg} / \mathrm{day}^{a}$

\begin{tabular}{|lccccc|} 
& \multicolumn{2}{c}{ All Subjects $(n=4,112)$} & & \multicolumn{2}{c|}{$\begin{array}{c}\text { Subjects With Intake }>50 \mathrm{mg} / \text { day } \\
(n=333)\end{array}$} \\
\cline { 2 - 3 } \cline { 5 - 6 } Food & Percent (rank) & Cumulative Percentage & & Percent (rank) & Cumulative Percentage \\
\hline Tea & $48.1(1)$ & 48.1 & & $38.8(2)$ & 38.8 \\
Onions & $28.9(2)$ & 77.0 & & $43.4(1)$ & 82.2 \\
Apples & $7.1(3)$ & 84.1 & & $3.2(4)$ & 85.5 \\
Kale & $3.6(4)$ & 87.7 & & $9.0(3)$ & 94.5 \\
French beans & $2.9(5)$ & 90.6 & & $1.1(6)$ & 95.6 \\
Endive & $2.2(6)$ & 92.8 & & $1.5(5)$ & 97.1 \\
Red wine & $0.9(7)$ & 93.7 & $0.4(7)$ & 97.5 \\
Applesauce & $0.7(8)$ & 94.4 & $0.3(8)$ & 97.9 \\
Oranges & $0.6(9)$ & 95.0 & $0.3(9)$ & 98.2 \\
Leek & $0.5(10)$ & 95.5 & $0.3(10)$ & 98.5 \\
\hline a: Flavonoid intake is sum of quercetin, kaempferol, myricetin, apigenin, and luteolin. & \\
\hline
\end{tabular}

\section{Discussion}

To our knowledge, this is the first estimation of the intake of flavonoids in a large population sample by use of analytic data obtained by HPLC. Kühnau (23) estimated that the average intake of all flavonoids combined was approximately $1 \mathrm{~g} / \mathrm{day}$, of which about $170 \mathrm{mg}$ (expressed as glycosides) were flavonols, flavones, and flavanones. This is approximately 115 mg expressed as aglycons such as quercetin. This estimation was based on the average American diet as accounted for in the Food Consumption Statistics 1955-1971 of the Organization for Economic Cooperation and Development (OECD, Paris, 1973). These values have been widely quoted (1-19). Our results, expressed as aglycons, suggest that the intake of flavonols and flavones in a Western population is approximately fivefold lower than Kühnau's estimate, but a direct comparison between the two values is difficult. We did not include flavanones in our analysis, because no studies have reported anticarcinogenic activities of this class of flavonoids. Because the occurrence of flavanones is limited to citrus fruits at levels between 70 and $160 \mathrm{mg} / \mathrm{kg}$ (33), resulting in a mean intake of $5 \mathrm{mg} / \mathrm{day}$ on the basis of our data, they cannot account for the large difference between our results and the estimation of Kühnau. It is more likely that the high values reported by Kühnau are due to an overestimation of the flavonoid content of foods. The estimation of Kühnau was based on 
techniques now considered inappropriate, the most advanced being thin-layer chromatography followed by a spectrophotometric measurement. In addition, these data were based on analyses of the whole foods as opposed to analyses of the edible parts in our study. In general, our values obtained by HPLC (26-28) are considerably lower than those cited by Kühnau. Moreover the OECD Food Consumption Statistics used by Kühnau are based on food disappearance values, which overestimate the intake of foods. Changes in dietary practices between 1971 and 1988 would, rather, suggest a higher intake of flavonoids in The Netherlands in 1988 because of the increased consumption of vegetables and fruits in this period. It is unlikely that we missed important potential sources of flavonoids, because we included all foods of vegetable origin consumed at an average level of $>1 \mathrm{~g} /$ day.

Quercetin is quantitatively the most important of the five flavonoids investigated, followed by kaempferol. Myricetin, luteolin, and apigenin are far less important. Quercetin is the predominant flavonoid found in foods, and, as a consequence, it has been used in most studies investigating physiological and biologic effects of flavonoids. Tea was the most important contributor to total flavonoid intake, followed by onions and apples (cumulative percentage 84 ) in this population. Because consumption of tea, onions, and apples does not vary between the seasons, seasonal variability in flavonoid intake was low.

Average tea consumption of the total population was approximately 2 cups/day (294 \pm $310 \mathrm{ml}$ ), average onion consumption was $16 \pm 32 \mathrm{~g} / \mathrm{day}$, and average apple consumption was $45 \pm 71 \mathrm{~g} /$ day. The range of flavonoid intake was very large; we found an approximately tenfold difference between the 10th and the 90th percentile. Participants with a zero flavonoid intake had a vitamin $C$ intake of $29 \mathrm{mg} /$ day, which is less than half the intake of vitamin $C$ in the rest of the subjects ( $77 \mathrm{mg} /$ day). The higher intake in women and in older age groups could be explained by a higher tea consumption. Onion and apple consumption was comparable in men and women. Consumption of onions was lower in older age groups, whereas consumption of apples was virtually constant over the four age groups. Heavy smokers had a lower flavonoid intake than nonsmokers or light smokers, which could be explained by a low consumption of tea and apples by heavy smokers. Onion consumption was approximately the same in the three smoking groups. Vegetarians consumed more tea, apples, and onions than nonvegetarians, which explains their high intake of flavonoids.

We conclude that flavonoids and especially quercetin are common components of the human diet. Unexpectedly, tea was the major contributor of flavonoids in this population, and the contribution of all vegetables combined, including onions at $29 \%$, was approximately $40 \%$. Thus the foods often associated with low rates of cancer in epidemiological studies, such as green-yellow vegetables and cruciferous vegetables (31), are not major sources of flavonoids in this population. However, in populations with other dietary practices, the importance of contribution of various foods may be different. In experimental animal studies, polyphenolic compounds in tea, such as quercetin, had anticarcinogenic effects $(34,35)$. In epidemiological studies, little attention has been paid to the effects of tea on carcinogenesis, and the results are conflicting (36).

In adults, mean intake of the five antioxidant flavonoids combined is $23 \mathrm{mg} /$ day. Intake of flavonoids thus exceeds that of other dietary antioxidants such as $\beta$-carotene $(2-3 \mathrm{mg} /$ day $)$ and vitamin $\mathrm{E}(7-10 \mathrm{mg} /$ day) and equals approximately one-third of that of vitamin C (70-100 $\mathrm{mg} /$ day) $(30,31)$. Furthermore, flavonoids are heat stable, and losses due to cooking and frying are low (unpublished observations). Thus flavonoids make a major contribution to the antioxidant potential of the diet in Western populations. Flavonoid intake was only weakly correlated with the intake of vitamin C, vitamin A (retinol equivalents), and dietary fiber, which have traditionally been regarded as cancer-protective factors in vegetables and fruits. This lack of intercorrelation offers the possibility to study the anticarcinogenic effects of flavonoids in epidemiological studies without the pitfalls of multicollinearity. Antioxidant 
flavonoids such as quercetin also inhibited oxidation and cytotoxicity of low-density lipoproteins in vitro $(37,38)$, which may decrease their atherogenicity and, subsequently, risk of coronary heart disease (39). It is therefore of interest to study the relationship between flavonoid consumption and the risk of chronic diseases in an epidemiological context.

\section{Acknowledgments and Notes}

The authors thank Edith Feskens and Ida Miedema for comments on earlier versions of the manuscript, Caroline Kok and Arianne Bijl for assistance in data analysis, and the Secretary of the Committee for Stimulation of the Use of Data from the Dutch National Food Consumption Survey. This project was supported by a grant from The Netherlands Ministry of Agriculture, Nature Management and Fisheries. Address reprint request to Dr. Michaël G. L. Hertog, Dept. of Chronic Diseases and Environmental Epidemiology, National Institute of Public Health and Environmental Protection, PO Box 1, NL-3720 BA Bilthoven, The Netherlands.

Submitted 2 December 1992; accepted in final form 5 February 1993.

\section{References}

1. Letan, A: "Relation of Structure to Antioxidant Activity of Quercetin and Some of Its Derivatives." J Food Sci 31, 518-23, 1966.

2. Ramanathan, L, and Das, NP: "Studies on the Control of Lipid Oxidation in Ground Fish by Some Polyphenolic Natural Products." J Agric Food Chem 40, 17-21, 1992.

3. Robak, J, and Gryglewski, RJ: "Flavonoids Are Scavengers of Superoxide Anion." Biochem Pharmacol 37, 83-88, 1988.

4. Husain, SR, Cillard, J, and Cillard, P. "Hydroxy Radical Scavenging Activity of Flavonoids." Phytochemistry 26, 2489-2492, 1987.

5. Cerutti, PA: "Prooxidant States and Tumor Promotion." Science 227, 375-381, 1985.

6. Fujiki, H, Horiuchi, T, Yamashita, K, Hakii, H, Suganuma, M, et al.: "Inhibition of Tumor Promotion by Flavonoids." In Plant Flavonoids in Biology and Medicine: Biochemical, Pharmacological and Structure-Activity Relationships, V Cody, E Middleton, and JF Harbone (eds). New York: Liss, 1986, pp. 213, 429-440.

7. Deschner, EE, Ruperto, J, Wong, G, and Newmark, HL: "Quercetin and Rutin as Inhibitors of AzoxymethanolInduced Colonic Neoplasia." Carcinogenesis 7, 1193-1196, 1991.

8. Mukhtar, H, Das, M, Khan, WA, Wang, ZY, Bik, DP, et al.: "Exceptional Activity of Tannic Acid Among Naturally Occurring Plant Phenols in Protecting Against 7,12 Dimethylbenz[a]anthracene-, Benzo[a]pyrene-, 3-Methylcholanthrene-, and $N$-Methyl-N-Nitrosourea-Induced Skin Tumorigenesis in Mice." Cancer Res 48, $236 \mathrm{I}-2365,1988$.

9. Verma, AK, Johnson, JA, Gould, MN, and Tanner, MA: "Inhibition of 7,12-Dimethylbenz[a]anthracene and $N$-Nitrosomethyiurea Induced Rat Mammary Cancer by Dietary Flavonol Quercetin." Cancer Res 48, 5754-5788, 1988.

10. Wei, H, Tye, L, Bresnick, E, and Birt, DF: "Inhibitory Effect of Apigenin, a Plant Flavonoid, on Epidermal Ornithine Decarboxylase and Skin Tumor Promotion in Mice." Cancer Res 50, 499-502, 1990.

11. Hosokawa, N, Hosokawa, Y, Sakai, T, Yoshida, M, Marvi, N, et al.: "Inhibitory Effect of Quercetin on the Synthesis of a Possibly Cell-Cycle-Related 17-kDa Protein in Human Colon Cancer Cells." Int $J$ Cancer 45, 1119-1124, 1987.

12. Ranelletti, FO, Ricci, R, Larocca, LM, Maggiano, N, Capelli, A, et al.: "Growth-Inhibitory Effect of Quercetin and Presence of Type-II Estrogen-Binding Sites in Human Colon Cancer Cell Lines and Primary Colorectal Tumors." Int $J$ Cancer 50, 486-492, 1992.

13. Bjeldanes, LF, and Chang, GW: "Mutagenic Activity of Quercetin and Related Compounds." Science 197, 577-578, 1977.

14. Nagao, M, Morita, N, and Yahagi, T: "Mutagenicity of 61 Flavonoids and Related Compounds." Environ Mutagen 3, 401-419, 1991.

15. Aeschbacher, HU, Meier, H, and Ruch, E.: "Nonmutagenicity In Vivo of the Food Flavonol Quercetin." Nutr Cancer 4, 90-98, 1982.

16. Pamucku, AM, Yalçiner, S, Hatcher, JF, and Bryan, GT: "Quercetin, a Rat Intestinal and Bladder Carcinogen Present in Bracken Fern (Pteridium aquilinium)." Cancer Res 40, 3468-3472, 1980.

17. Hirono, I, Ueno, I, Hosaka, S, Takanashi, H, Matsushima, T, et al.: "Carcinogenicity Examination of Quercetin and Rutin in ACI Rats." Cancer Lett 13, 15-21, 1981.

18. Morino, K, Matsukura, N, Ohgaki, H, Kawachi, T, Sugimura, T, et al.: "Carcinogenicity Test of Quercetin and Rutin in Golden Hamsters by Oral Administration." Carcinogenesis 3, 93-97, 1982. 
19. Saito, D, Shirai, A, Matsushima, T, Sugimura, T, and Hirono, I: "Test of Carcinogenicity of Quercetin, a Widely Distributed Mutagen in Food." Teratog Carcinog Mutagen 1, 213-221, 1980.

20. Steinmetz, KA, and Potter, JD: "Vegetables, Fruits, and Cancer. I. Epidemiology." Cancer Causes Control 2, 325-357, 1991.

21. Steinmetz, KA, and Potter, JD: "Vegetables, Fruits, and Cancer. II. Mechanisms." Cancer Causes Control 2, 427-442, 1991.

22. Wattenberg, LW: "Chemoprevention of Cancer." Cancer Res 45, 1-7, 1985.

23. Kühnau, J: "The Flavonoids, a Class of Semi-Essential Food Components, Their Role in Human Nutrition." World Rev Nutr Diet 24, 117-120, 1976.

24. Herrmann, K: "Flavonols and Flavones in Food Plants, a Review." J Food Technol 11, 433-448, 1976.

25. Herrmann, K: "On the Occurrence of Flavonol and Flavone Glycosides in Vegetables." $Z$ Lebensm -Unters Forsch 186, 1-5, 1988.

26. Hertog, MGL, Hollman, PCH, and Venema, DP: "Optimization of a Quantitative HPLC Determination of Potentially Anticarcinogenic Flavonoids in Vegetables and Fruits." J Agric Food Chem 40, 1591-1598, 1992.

27. Hertog, MGL, Hollman, PCH, and Katan, MB: "Content of Potentially Anticarcinogenic Flavonoids of 28 Vegetables and 9 Fruits Commonly Consumed in The Netherlands." J Agric Food Chem 40, 2379-2383, 1992.

28. Hertog, MGL, Hollman, PCH, and Van de Putte, B: "Content of Potentially Anticarcinogenic Flavonoids of Tea Infusions, Wines, and Fruit Juices." $J$ Agric Food Chem. In press.

29. Hulshof, K, and Van Staveren, WA: "The Dutch National Food Consumption Survey, Design Methods and First Results." Food Policy 16, 257-260, 1991.

30. US Department of Agriculture: "Nutrient Intakes. Individuals in 48 States, Years 1977-1978." In Nationwide Food Consumption Survey. Hyattsville, MD: Consumer Nutrition Div, Human Nutrition Information Service, US Dept of Agriculture, 1984. (Rep I-2)

31. Block, G, Patterson, B, and Subar, A: "Fruit, Vegetables, and Cancer Prevention: A Review of the Epidemiological Evidence." Nutr Cancer 17, 1-29, 1992.

32. SAS/STAT User's Guide, Release 6.03. Cary, NC: SAS Institute, 1988.

33. Balestieri, F, Flori, A, and Marini, D: "Strategies for Food Quality Control and Analytical Methods in Europe." Proc 6th Cur Conf Food Chem Lebensmittelchemische Gesellschaft, Frankfurt am Main 1991, pp 369-378.

34. Mukhtar, H, Wang, ZY, Kativar, SK, and Agarwal, R: "Tea Components, Antimutagenic and Anticarcinogenic Effects." Prev Med 21, 351-360, 1992.

35. Stich, HF: "Teas and Tea Components as Inhibitors of Carcinogen Formation in Model Systems and Man." Prev Med 21, 377-384, 1992.

36. La Vecchia, C, Negri, E, Franceschi, S, D’Avanzo, B, and Boyle, P: "Tea Consumption and Cancer Risk." Nutr Cancer 17, 27-31, 1992.

37. De Whalley, CV, Rankin, SM, Hoult, JRS, Jessup, W, and Leake, DS: "Flavonoids Inhibit the Oxidative Modification of Low Density Lipoproteins by Macrophages." Biochem Pharmacol 39, 1743-1750, 1990.

38. Negre-Salvagyre, A, and Salvagyre, R: "Quercetin Prevents the Cytotoxicity of Oxidized Low-Density Lipoproteins by Macrophages." Free Radical Biol Med 12, 101-106, 1992.

39. Steinberg, D, Parthasarathy, S, Carew, TE, Khoo, JC, and Witztum, JL: "Modifications of Low-Density Lipoprotein That Increase Its Atherogenicity." N Engl J Med 320, 915-924, 1989. 